\title{
A study of human resource policies and practices for primary health care system in Delhi
}

Background: A comprehensive health care services requires effective human resource (HR) management policy to ensure organizational success. Government is primarily concerned with the size of the workforce rather than the contemporary HR practices. This resulted into lack of attention to HR management in health sector. Objective: To critically examine HR policies and practice for primary health care system in Delhi. Materials and Methods: For critical analysis of HR policies and practices for primary urban health centers, related documents were examined from year 2005 to 2012. The policies and practices were examined with reference to HR planning, recruitment, selection, hiring, staffing, probation, induction training, performance evaluation, salary and transfer policy in the organization. Results: At present, updated HR planning is not done regularly and due to lack of such updated information actual HR requirement is not calculated leading to shortage backlog. To fill up this shortage contractual model to recruit staff has been adopted by health department. There is no induction training and training need assessment done in the organization. There is wide disparity in pay and leave provisions for different category of regular and contractual staff working under the same roof of health facilities. Conclusion: Disparity in salary, leave provision and other privileges in organization have brought discrimination and demotivation among employees. To deal with conflicting climate in organization comprehensive HR policy is suggested. Policy content should include HR planning, training and development, institute capacity building, HR information

Pawan Kumar, Anu Mehra', Deep Inder', Abdul Majeed Khan ${ }^{3}$

Department of Community Health Administration and ${ }^{3}$ Social Sciences, National Institute of Health and Family Welfare, Munirka, 'Law Centre-1, Faculty of Law, University of Delhi,

${ }^{2}$ Department of Pharmacology, FOD, Jamia Millia Islamia, New Delhi, India

Address for the Correspondence:

Dr. Pawan Kumar,

B-10, 1-A, Transit Officers Flat, Battery Lane, Rajpur Road, New Delhi-110 054, India. E-mail: drpawan2000@gmail.com

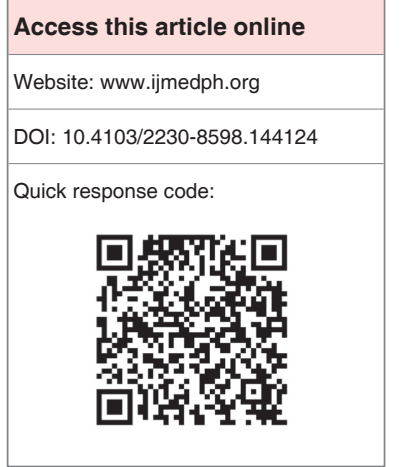
system, motivation, and retention strategies for HR.

Key words: Contract, Delhi, health care, human resource

\section{INTRODUCTION}

Human resource (HR) is indispensable for the health sector. Public health organization needs to ensure that all the employees feel their job as source of happiness. A comprehensive health care provision requires effective HR management policy to ensure organizational success. The World Health Report (2006) has given important boost to the global agenda for human resources for health $(\mathrm{HRH}) .^{[1]}$ Government, which is directly or indirectly funding the majority of health care expenditure has been primarily concerned with macroeconomic issues, especially size of the workforce rather than the micro level focus of contemporary HR practices. This resulted into the lack of attention to HR management in health which has direct effect on motivation and performance of the workforce. ${ }^{[2]}$

Human resource policies and practices are concerned with employee's selection practices, training and development program and performance evaluation system. ${ }^{[3]} \mathrm{HR}$ policies defined by Armstrong as the continuing guidelines the organization intends to adopt in managing its people. ${ }^{[4]} \mathrm{HR}$ policies define the values of the organization to how people should be treated. From these, principles are derived for health managers to how to deal with HR matters. Therefore, HR policies serve a reference point for employment practices and decisions are being made about people. ${ }^{[4]} \mathrm{HR}$ policies guides the actions required for achieving the objectives of the organization. Therefore, study was conducted with an aim to critically analyze HR policies and practice under primary health care system in Delhi. The study would help in re-introspection of the terms and conditions of engaging/hiring/recruiting HRs and use of HR management principles to address the job outcome and enhance job satisfaction and motivation. 


\section{MATERIALS AND METHODS}

Descriptive study was conducted in primary health care system of Delhi where primary health care is provided by primary urban health centers (PUHCs) under state Government. Health services are headed at state level by Director of Health Services (DHS) and at district level by Chief District Medical Officers (CDMOs). Delhi health services under DHS are divided into 9 districts (as on 31.07.2012) and in each district PUHCs are administratively controlled by CDMOs. The PUHCs have HR like Medical Officers (MOs), Pharmacists, Auxiliary Nurse and Midwifes (ANMs), laboratory technicians (LT) and Laboratory Assistants both on regular and contractual basis to deliver the health care services. ${ }^{[5]}$ For critical analysis of HR policies and practices related documents for the reference period from 2005 to 2012 were examined using observation check list. The documents were procured from the office of DHS, CDMO, Director Family Welfare (DFW), Delhi State Health Mission (DSHM), and website of Delhi Government Health Department. Various documents examined were: Practices for HR hiring, office orders, office memorandums, minutes of meetings, recruitment rules (RRs), offer cum appointment letters, terms and conditions of staff hiring, newspaper advertisements, PUHC standards and DHS dispensary manual and Central Civil Service (CCS) Rules. The HR policies and practices were examined on parameters like: HR planning, recruitment, selection, hiring and staffing, probation, induction training, performance evaluation, compensation (like wages, salary, rewards, recognition, remuneration, pay benefits etc.), and pension scheme and transfer policy in the organization. Interview of middle and top level health managers, health care providers were also conducted to fill up the gap in information and to explore their opinion about HR policies and practices. After examining the documents analysis was made and presented in the form of tables and text in the results.

\section{RESULTS}

The policies and practices for regular and contractual HR were examined on the various parameters, which are detailed as follows:

\section{Human resource planning}

Human resource planning for regular staff is done by planning department in the DHS and Delhi Secretariat. The RRs such as qualification, experience (essential and desirable) are framed if existing ones do not cover the post. The Administrative Reform Department scrutinizes the work load and after concurrence of planning and finance departments the posts are created.

For contractual staff, demand comes from CDMO office, which is compiled at State Program Management Unit of DSHM and thereafter HR demand is projected in State Program Implementation Plan (PIP) of Delhi to Ministry of Health and Family Welfare (MoHFW), Government of India. After approval of PIP for state, required HR posts are filled for that particular financial year. However, at present updated HR planning is not happening in health department. For HR planning, every 2 years assessment of work load and number of posts needs to be done regularly. However, due to lack of such updated information, actual HR requirement is not calculated; and shortage backlog is increasing continuously; and to fill up this shortage contractual model to recruit staff has been adopted by Department of Health and Family Welfare. Under contractual model recruitment is done for $11^{\text {th }}$ month to 1 year. But in practice, the contractual staff is continued for years and regular posts are not filled for longer duration.

\section{Recruitment}

For gazetted post like MOs, requisition for requirement is sent to Union Public Service Commission's (UPSC). Delhi Subordinate Service Selection Board (DSSSB) is responsible for the recruitment of nongazetted posts like ANMs, Pharmacists, Lab Assistants, and Lab Technicians. Under National Rural Health Mission (NRHM) the recruitment is done by State Health Society and Integrated District Health Society for 11 months and contract is renewed after satisfactory performance of employees for further 11 months. Under primary health care system three types of staff are working:

1. Regular staff,

2. DHS recruited contractual staff

3. Contract staff under NRHM and all having different terms and conditions for recruitment.

\section{Probation}

Probation is governed by CCS Rules ${ }^{[6,7]}$ for regular category of staff. There is no induction training during probation period, it is perhaps presumed that people recruited are professionals and they know their job. Probationer employee is supposed to perform his or her duties directly on job from very $1^{\text {st }}$ day. With progression of time employee try to understand what the organization is supposed to do in health care delivery system. No formal training is imparted to employees at the time of joining so health care providers do their work as they understand without any objective in mind.

\section{Trainings}

Training is provided to MOs and paramedical staff whenever a new program is launched. No formal training need assessment is done every year. Under NRHM training calendar is prepared for specific programs. ${ }^{[8]}$ DHS has CME cell, which is also engaged in imparting the training during service on various themes. Few training are conducted at DHS Head Quarter and many a times it nominates the names of officers and officials for trainings to the other agencies like Indira Gandhi National Open University. ${ }^{[9]}$ Reproductive and Child Health $(\mathrm{RCH})$ related trainings are conducted at training school of family welfare training center, which is working under DFW. For administrative trainings nominations are sent to Union Territory Civil Service training center. ${ }^{[9]}$ There is provision of study leave for MOs only who are recruited through UPSC under Central Health Services. For paramedical staff like ANMs, Pharmacists and Lab assistants (LAs) or LTs, there is no provision of study leave as no guidelines are framed by the department. However, for contractual staff no 
provision for study leaves or long duration trainings is provisioned under terms and conditions of hiring.

\section{Compensation/reward and recognition}

For Regular employees like MOs, ANMs, Pharmacists and Lab Assistants and Lab Technicians, the salary and increments' are paid as per CCS rules. ${ }^{[6,7]}$ Salary structure of different category of staff is shown in Table 1. As evident from the Table 1, there is wide disparity in pay provision for different category of staff and working under the same roof of health facility. For contractual staff salary is fixed and there is no provision of enhancement every year. The benefits like leave travel concession (LTC), medical reimbursement (except for DHS contract only), transport allowance, pensioner benefits, group insurance, study leave and child care leave etc., are for regular employees only. For regular Paramedical employees Modified Accelerated Career Progression scheme is there at 10, 20 and 30 years of service and there is no change in designation of ANM, LA, Pharmacist. These categories of staff join as such and retire with these designations only. Regular MO has time bound promotions under dynamic accelerated career progression scheme. There is wide disparity in leave provisions under different types of contract for the same kind of job under same organization as shown in Table 2.

\section{Pension and other conditions of service}

Officers and officials appointed prior to 1.1.2004 are governed by CCS (Pension) Rules 1972. ${ }^{[10]}$ Officers or officials appointed after 1.1.2004 are governed by New Pension Scheme. However, there is no contribution from the Government in respect of individuals who are not Government employees like contractual employees.

\section{Annual appraisal reports}

Appraisal reports are more of subjective rather than objective and need modification and change for contractual and regular staff.

\section{Transfer policy}

As per terms and conditions of recruitment of regular employees they are required to work in any department under health in Delhi. The contractual staff is required to work under respective health society who has given the initial offer and appointment letter. At present there is no transfer policy in health department. Summary of critical examination of HR policies and practices for primary health care system is briefly tabulated in Table 3.

\section{Issues and perspective of human resource practices}

The ultimate goal of HR planning is to facilitate enabling environment in the organization for optimal performance/achievement. It is believed that the potential of HR, unless capitalized fully by the definite justified principles in the organization, one can't achieve the ultimate goal of an organization. The organizations are generally structured in hierarchical order but the production/achievement is accomplished by dedicated team work culture at the lowest unit in the hierarchy. The upper layer of the organization develops policies and programs and creates facilities for the employees of the organization. The unity and diversity at the lowest units of the organizational structure depends a lot on the principles followed at higher level in terms of the employees' selection and their development, definite package of privileges including salary, promotion, incentive, reward and other facilities such as medical reimbursement, study leave, housing, pension, LTC etc. An organization can ensure team work culture at the lowest level if it follows definite principles. However, any system, which is conglomeration of employees appointed on

\begin{tabular}{|c|c|c|c|c|}
\hline Type of staff & MO & ANMs & Pharmacists & LAs \\
\hline Regular staff (pay/month) & $\begin{array}{l}\text { Rs. } 15,600-39,100+G P \\
\text { 5400/-=Total: Rs. } 57,000 /-\end{array}$ & $\begin{array}{l}\text { Rs. } 5200-20,200+G P \\
2400=\text { Total: Rs. } 26,829 /-\end{array}$ & $\begin{array}{l}\text { Rs. } 5200-20,200+G P \\
2800=\text { Total: Rs. } 25,972 /-\end{array}$ & $\begin{array}{l}\text { Rs. } 5200-20,200+G P \\
2400=\text { Total: Rs. } 22,662 /-\end{array}$ \\
\hline $\begin{array}{l}\text { DHS recruited contractual } \\
\text { staff (pay/month) }\end{array}$ & Rs. $53,000 /-$ fixed & Rs. $11,476 /-$ fixed & Rs. $12,080 /$ - fixed & Rs. $11,476 /$ - fixed \\
\hline $\begin{array}{l}\text { Contract staff under NRHM } \\
\text { (pay/month) }\end{array}$ & Rs. $43,500 /-$ fixed & Rs. $14,203 /$ - fixed & Rs. $15,410 /$ - fixed & Rs. 14,203/- fixed (for LTs) \\
\hline
\end{tabular}

PUHC = Primary urban health center, GP = Grade pay, DHS = Director of health services, NRHM = National rural health mission, LTs = Laboratory technicians, ANM = Auxiliary nurse and midwife, $\mathrm{MO}=$ Medical officer, $\mathrm{LA}=$ Lab assistant

\section{Table 2: Leave provisions to different types and category of staff in PUHCs (as on 31.7.2012)}

\begin{tabular}{ll} 
Type of staff & MOs \\
\hline Regular staff & $\begin{array}{l}\text { 8 days CLs+2 RHs, 30 } \\
\text { days earned leave+10 days } \\
\text { commuted leave+6 months } \\
\text { maternity leave }\end{array}$ \\
DHS recruited & $\begin{array}{l}1 \text { day CL per month and } 30 \text { days } \\
\text { leaves without pay in a year } \\
\text { contractual staff }\end{array}$ \\
Contract staff & $\begin{array}{l}21 / 2 \text { days leave per month of } \\
\text { completed service }\end{array}$
\end{tabular}

\section{ANMs}

8 days $\mathrm{CLs}+2 \mathrm{RH}, 30$ days

earned leave +10 days commuted leave+6 months maternity leave

$2 \frac{1}{2}$ and half days leave per month of completed service

$2 \frac{1}{2}$ days leave per month of completed service

\section{Pharmacists}

8 days $\mathrm{CLs}+2 \mathrm{RH}, 30$ days

earned leave +10 days

commuted leave +6 months

maternity leave

$2 \frac{1}{2}$ days leave per month

of completed service

$2 \frac{1}{2}$ days leave per month

of completed service

\section{LAs}

8 days $\mathrm{CLs}+2 \mathrm{RH}, 30$ days earned leave+10 days commuted leave +6 months maternity leave

$2 \frac{1}{2}$ days leave per month of completed service

$2 \frac{1}{2}$ days leave per month of completed service

DHS = Director of health services, CLs = Casual leaves, $\mathrm{RHs}=$ Restricted holidays, PUHC = Primary urban health center, NRHM = National rural health mission, ANM = Auxiliary nurse and midwife, $\mathrm{MO}=$ Medical officer, LA = Lab assistant 


\begin{tabular}{|c|c|c|}
\hline $\begin{array}{l}\text { HRM } \\
\text { component }\end{array}$ & Policies and practices & Remarks \\
\hline HR planning & $\begin{array}{l}\text { Regular HR: Planning department makes plans for recruitment. Demand } \\
\text { comes from individual department. The TOR, that is recruitment rules which } \\
\text { is, qualification experience (essential and desirable) are framed if existing } \\
\text { ones do not cover the post. The AR department scrutinizes the work load } \\
\text { and gives clearance for creation of new posts } \\
\text { For contractual staff demand comes from CDMO office, which is compiled } \\
\text { at SPMU (DSHM level) and HR demand is projected in state PIP to, GOI, if }\end{array}$ & $\begin{array}{l}\text { No continuous HR planning is happening in } \\
\text { organization } \\
\text { No formal assessment of work load for extra } \\
\text { HR demanded from NRHM is done } \\
\text { The initial practice of contractual employment } \\
\text { was started in RCH program and thereafter this } \\
\text { practice is continued }\end{array}$ \\
\hline
\end{tabular}

Recruitment For gazetted post like MOs requirement is sent to UPSC. DSSSB is responsible for recruitment of nongazetted posts like ANM, pharmacists, LAs and lab technicians. Advertisement is placed in prominent newspapers and minimum 2 months' time is given for the response In case of gazetted post UPSC don't recruit HR in time. In that case with the approval of competent authority which is the LG, appointment is done on contract basis till a regular person joins

Under NRHM recruitment is done by State Health Society or IDHS for 11 months and the contract is extended after satisfactory performance of employee 2010 onwards PUHC standards have been laid down for staffing of PUHCs in Delhi

Probation Probation of employees is governed by CCS rules. There is no provision of induction training as it is assumed that employee knows the job. During probation employee is supposed to perform his or her duties directly

Training

Training is provided for all MOs and Paramedical staff whenever a new program is launched. No formal training need assessment is done Under NRHM training calendar is prepared for specific program related trainings only DHS has CME cell which is also engaged in imparting the in service trainings

Compensation For regular employees like MOs, ANMs, pharmacists and LAs and lab technicians the salary and increments' are laid down in CCS rules For regular MO initial salary is Rs. 15,600-39,100+GP 5400/- (total Rs. 57,000/-) for regular ANM Rs. 5200-20200+GP 2400 (total Rs. 26,829/-), for regular pharmacists Rs. 5200-20,200+GP 2800 (total Rs. 25,972/-), for regular LA Rs. 5200-20,200+GP 2400 (total Rs. 22,662/-) (as on 31.7.2012) For contractual HR consolidated fixed salary is given

MO contract recruited under DHS is Rs. 53,000/- fixed, ANM Rs. 11,476/-, pharmacists Rs. 12,080/-, for LA Rs. 11476/- per month MO under NRHM is Rs. 43,500/-, ANM is Rs. 14,203/-, pharmacists is Rs. 15,410/-, LT is Rs. 14,203/- fixed per months Leave provisions for NRHM HR are like 2.5 leaves/month and DHS recruited staff like $\mathrm{MO}$ has one leave per month, and paramedical staff can avail $2 \frac{1}{2}$ day leave per month for completed service

Pension Officers and officials appointed prior to 1.1.2004 are governed by CCS (pension) rules 1972

Transfer No documented and written transfer policy for employees in health policy
No document
department
Till 2010 staffing was done on old criteria. No formal document could be retrieved from DHS $\mathrm{HQ}$ to examine the staffing pattern After 2010 onwards PUHCs norms are laid down and HR is hired and recruited on the basis of new pattern

PUHC standards have been approved by cabinet in Delhi for the primary health care system

Different types of recruitment by DHS or IDHS, terms and conditions are varying for same kind of job

The probation period for regular MO, ANM, duration of contract period for DHS staff is 1 year and for district health societies 11 months No induction training provision for any kind of primary health care providers exists

Some Training are conducted at DHS HQ $\mathrm{RCH}$ related trainings are conducted at Training

Some training being conducted at UTCS training center

Wide disparity in pay provision for different category of staff and working under the same roof of health facility

Disparity in leave provisions under different types of contract for same kind of job under same organization

Salary is fixed and no fixed provision of enhancement every year

No other benefits like LTC, medical reimbursement, transport allowance etc. For regular paramedical employees MACPs provision is there at $10,20,30$ years of service and there is no change in designation of ANM, LA, pharmacist etc.

Regular $\mathrm{MO}$ has time bound promotions like SMO, CMO, CMO (NFSG) and CMO (SAG)

After 1.1.2004 new pension Scheme is implemented for regular employees. No such provision of contractual staff

Some initiatives have been started by Health and Family Welfare department to frame transfer policy in 2011 pharmacists and LAs is for 2 years however, school of FW under DFW

HRM = Human resource management, $\mathrm{PUHCS}=$ Primary urban health center, HR = Human resource, DHS = Director of health services, NRHM = National rural health mission, $\mathrm{GP}=$ Grade pay, $\mathrm{MO}=$ Medical officer, $\mathrm{SMO}=$ Senior medical officer, $\mathrm{CMO}=$ Chief medical officer, $\mathrm{LTC}=\mathrm{Leave}$ travel concession, $\mathrm{LA}=\mathrm{Lab}$ assistant, $\mathrm{LT}=\mathrm{Laboratory}$ technician, $\mathrm{ANM}=$ Auxiliary nurse and midwife, $\mathrm{CME}=$ Continue medical education, $\mathrm{DFW}=$ Director of family welfare, $\mathrm{AR}=\mathrm{Administrative} \mathrm{reform}, \mathrm{CDMO}=\mathrm{Chief}$ district medical officer, SPMU = State program management unit, DSHM = Delhi state health mission, PIP = Program implementation plan, GOI = Government of India, HQ = Head quarter, $\mathrm{IDHS}=$ Integrated district health society, UPSC = Union public service commission, DSSSB = Delhi subordinate service selection board, LG = Lieutenant governor, CCS = Central civil service, FW = Family welfare, SAG = Senior administrative grade, NFSG = Nonfunctional selection grade, MACP = Modified accelerated career progression, UTCS $=$ Union territory civil service, $\mathrm{TOR}=$ Terms of reference, $\mathrm{RCH}=$ Reproductive and Child Health

different criteria, pay and pay package can't ensure unity work culture. In organization, it is possible that some employees are motivated and others are de-motivated. In this case, the net motivating environment is the difference between motivating and demotivating forces. If the difference is higher toward positive side it indicates highly favorable environment in the organization and vice versa. In Delhi state, the 
employees working under primary health care system have got three differential identities because they are recruited by the three respective agencies; and these agencies create their own rules and regulations, terms and conditions. Those who are regular avail all the facilities and privileges as per government rules, whereas the staff recruited under contractual model do same work but on differential pay packages. Hence, these health care providers are different in their motivational profile for work. Such employees likely to spend more and more time for comparison and attribution rather than concentrating emotionally with the responsibilities they are given to perform in the organization. It is essential on the part of HR planners to advise to the concerned organizations about the major principles of HR development.

\section{DISCUSSION}

Human resources are essential element of a health system and it is an important organizational asset. Without HR management, it is not possible to achieve the Millennium Development Goals (MDGs) and other goals and objectives of NRHM. For achieving the MDGs, more focus is required for strengthening of HR in health. At present updated HR planning is not happening in health department. Due to lack of updated information in planning; actual HR requirement is not calculated; and backlog is increasing continuously. Similar finding was found in a study conducted by Central Bureau of Health Intelligence (CBHI) ${ }^{[11]} \mathrm{MoHFW}$ in Madhya Pradesh and Gujarat, where no formal mechanism for health workforce planning is existing. Study by CBHI revealed that decisions regarding creation of new posts and filling up of vacant posts are done as per the need and mostly program driven. Factors such as population growth, demographic changes, disease burden, patient load and health seeking behavior are not taken into consideration while doing HR planning in Madhya Pradesh and Gujarat. ${ }^{[1]]}$ Same way in Delhi these parameters are not taken into consideration and contractual posts are program driven under NRHM. Though PUHCs standards are in place where new staffing norms are devised, but not implemented in entire state as of now.

Union Public Service Commission's and DSSSB take longer time to complete the procedure of recruitment and selection of the staff. Similar findings were reported by CBHI, MoHFW in Gujarat, where backlog of a number of vacancies of doctors is increasing due to slow process of recruitment by the Gujarat Public Services Commission and it has allowed ad-hoc recruitment of doctors for $>8$ years. ${ }^{[1]}$ Similar findings are observed in present study. During probation period induction training is not imparted to probationers, and they perform their duties directly on job from the very $1^{\text {st }}$ day. Study by CBHI also revealed that training policy is pending in Gujarat. ${ }^{[11]}$

Compensation and reward system in Delhi show disparity in pay and allowances between regular and contractual staff. This has brought discrimination and demotivation in employees in PUHCs. There is wide disparity in pay provision for different category of staff and they are working under the same roof of health facility. For contractual staff salary is fixed and there is no provision of enhancement every year. The benefits like LTC, medical reimbursement (except for DHS contract only), transport allowance, pensioner benefits, group insurance, study leave and child care leave etc., are major cause of discrimination and lower satisfaction. Stagnation in career for paramedical workers is cause of dissatisfaction even in regular staff. Contractual staff feels that they are discriminated for leave provisions though they perform same kind of work in the organization. Similar constraints of difference in remunerations and other privileges between regular and contractual staff are reported for same kind of services from Punjab, Uttar Pradesh, Madhya Pradesh, and Manipur by Sixth CRM Report (2012)..$^{[12]}$

There is lack of transfer policy in the health department for HR. Review of documents revealed that transfers take place as per need and exigencies of department. There is no formal provision for the transfer of employees in the organization. Study conducted in Gujarat by CBHI, MoHFW also highlighted absence of transfer policy in health care system. ${ }^{[1]]}$ However in Madhya Pradesh, there is formal transfer policy in place. The rules prescribe minimum tenure of posting in one location and procedures for transfer are well documented. ${ }^{[1]}$ Importance of transfer policy is also highlighted by earlier study by Kumar et al. in 2013. ${ }^{[13]}$

\section{CONCLUSION}

Health care system is HR intensive, and delivery of services is linked with HR policies and practices. It also depends upon motivation and satisfaction of health care providers. Over the years, the planning exercise has been primarily focused on creation of new infrastructure and institutions. After the launch of NRHM, DSHM took steps to assess the vacancy and supply factors of HR. However, the organization has not assessed whether the existing terms and conditions of HR recruitment are attractive enough and what needs to be done to attract and retain the staff at various positions. The state health department despite having such a large workforce does not have a specialized HR department to guide on various HR functions. Staff working on ad hoc basis for longer duration is not given number of benefits, which are otherwise available to regular staff. This is a leading cause of dissatisfaction and demotivation among the contractual staff. In spite of well laid out rules and procedures of recruitment on regular basis, vacancies are filled by contractual method. The delay on the part of institutions such as UPSC and DSSSB etc., has been cited as the reason for larger backlog of vacancies. This is true to a great extent as these organizations are burdened with recruitment of staff for all departments of the State. The policy of appointing staff on contractual basis is seen as a short term and ad hoc solution to the actual requirement. Higher officials viewed the contractual system as a parallel system, which is imposed by national health programs in the country but in practice such staffs are posted for routine activities in the health care system. Comprehensive HR policy should be developed for health care system in the country. HR policy content should include HR planning, 
training and development, institute capacity building, HR information system, motivation and retention strategies, in-service trainings, vision and mission for HR. HR Policy should clearly define the priorities of organization to be achieved from HR in health. Policy should take care of issues emerged out in present study like; HR planning, privileges attached with job, disparity, career development, trainings, transfer policy and HR management. Regularization of contractual staff is recommended if already working staff fulfills the eligibility criteria as laid down. Creation of posts by the finance department for already exiting contractual staff working for $>3-5$ years in the organization is suggested. Considering all the recommendations listed above, primary health care system needs comprehensive HR policy keeping regular and contractual employees into account.

\section{REFERENCES}

1. World Health Report. Working Together for Health. Geneva: World Health Organization; 2006. Available from: http://www.who.int/whr/2006/whr06_ en.pdf. [Last accessed on 2014 Apr 14].

2. Bach S. HR and new approaches to public sector management: Improving HRM capacity. Prepared for the Global Health Workforce Strategy Group. Geneva: World Health Organization; 2001. Available from: http://www. who.int/health-servicesdelivery/human/workforce/papers/HR.pdf. [Last accessed on 2014 May 07].

3. Robbins SP, Judge TA, Sanghi S. Organizational Behavior. $13^{\text {th }}$ ed. New Jersey: Pearson Prentice Hall; 2009.

4. Armstrong M. A Hand Book of Human Resource Management Practice by Michael Armstrong. 10 $0^{\text {th }}$ ed. 120 Pentonville Road, UK: Kohan Page; 2009.

5. Organization Structure of Directorate of Health Services, Government of Delhi. Available from: http://www.delhi.gov.in/wps/wcm/connect/doit health/Health/Home/Directorate+of+Health+Services/. [Last accessed on 2014 May 07; Last updated on 2014 Mar 14].

6. Muthuswamy B. Swamy's Hand Book for Central Government Servants. Chennai: Swamy Publishers; 2012.

7. Muthuswamy B. Swamy's Compilation of FRSR, Part III, Leave Rules. Chennai: Swamy Publishers; 2012.

8. Delhi State NRHM Programme Implementation Plan for year 2012-13. Submitted to Ministry of Health and Family Welfare, Government of India, Nirman Bhawan, New Delhi; 2013. Available from http://www.pipnrhmmohfw.nic.in/PIP2012-13_files/state_delhi.htm. [Last accessed on 2014 Feb 25].

9. Continue Medical Education (CME) Cell. Directorate of Health Services, Government of Delhi. Available from: http://www.delhi.gov.in/wps/wcm/ connect/doit_health/Health/Home/Directorate+of+Health+Services/CME. [Last accessed on 2014 May 07; Last updated on 2014 Mar 14].

10. Muthuswamy B. Swamy's CCS (Pension) Rules with Supplement. Chennai: Swamy Publishers; 2011.

11. Managing Human Resources for Health in India: A Case Study of MP and Gujarat. Central Bureau of Health Intelligence (CBHI). New Delhi: DGHS, Ministry of Health and Family Welfare; 2007.

12. Sixth Common Review Mission Report. New Delhi: Ministry of Health and Family Welfare, Government of India, Nirman Bhawan; 2012.

13. Kumar P, Khan AM, Inder D, Sharma N. Job satisfaction of primary healthcare providers (public sector) in urban setting. J Family Med Prim Care 2013;2:227-33.

How to cite this article: Kumar P, Mehra A, Inder D, Khan AM. A study of human resource policies and practices for primary health care system in Delhi. Int J Med Public Health 2014;4:430-5.

Source of Support: Nil, Conflict of Interest: None declared. 